\title{
Health literacy: What we know and don't know - A literature perspective
}

\author{
Kim D. ${ }^{* 1}$, O'Connor S.J. ${ }^{2}$, Williams J.H. ${ }^{2}$, Opoku-Agyeman W. ${ }^{3}$, Chu D.I. ${ }^{4}$, Choi S. ${ }^{5}$ \\ ${ }^{1}$ Health Care Administration Program, College of Business, Idaho State University, Pocatello, Idaho, United States \\ ${ }^{2}$ Department of Health Services Administration, School of Health Professions, University of Alabama at Birmingham, \\ Birmingham, Alabama, United States \\ ${ }^{3}$ College of Health and Applied Human Science, University of North Carolina Wilmington, Wilmington, North Carolina, United \\ States \\ ${ }^{4}$ Division of Gastrointestinal Surgery, School of Medicine, University of Alabama at Birmingham, Birmingham, Alabama, United \\ States \\ ${ }^{5}$ Department of Health Care Administration, Trinity University, San Antonio, Texas, United States
}

Received: November 17, 2020

DOI: $10.5430 /$ jha.v9n6p12
Accepted: December 16, 2020 Online Published: December 22, 2020

URL: https://doi.org/10.5430/jha.v9n6p12

\begin{abstract}
Health literacy has become an important topic to discuss in the US healthcare system. Almost nine out of ten adults in the United States lack the knowledge and skills required to manage their health and prevent disease. While studies have shown the importance of health literacy, not may have explored its' history and conceptual roots. Hence, the purpose of this study is to address the gap in the literature by reviewing studies related to the past, present, and the effect of health literacy. The results have shown that inadequate health literacy does affect patients' general health and performance of the US healthcare system.
\end{abstract}

Key Words: Health literacy, Past, Present, Effect on society

\section{INTRODUCTION}

According to the Institute of Medicine, health literacy is defined as "the degree to which an individual has the capacity to obtain, communicate, process, and understand basic health information and services needed to make appropriate decisions for the better of his or her health". ${ }^{[1]}$ A study from the National Assessment of Adult Literacy shows that only 12 percent of adults in the United States have proficient levels of health literacy while 14 percent of adults, which accounts for about 30 million people, have below basic health literacy levels. ${ }^{[2]}$ More specifically, almost nine out of ten adults may lack the knowledge and skills needed to prevent disease and manage their health. ${ }^{[3]}$ The primary issue with health literacy is that patients do not understand the complex medical communication used in the delivery of care, which can cause a wide-range of negative consequences affecting disparities, care quality, and costs. ${ }^{[4]}$

While studies have shown the importance of health literacy, not many have explored its' history and conceptual roots. As it is important to know why and how major healthcare enactments, such as Medicare and Medicaid and the Affordable Care Act, have transpired, it can be equally important to find out the history, current status, and the effect of health literacy. Especially with COVID-19 impacting diverse patient popu-

\footnotetext{
${ }^{*}$ Correspondence: Kim D.H.; Email: danielkim@isu.edu; Address: Idaho State University, 921 South 8th Avenue, Pocatello, ID 83209, United States. 
lation and healthcare systems, the topic of health literacy has become more crucial for researchers to understand. While diverse studies have examined the effect of health literacy in specific medical fields, limited number of studies have conducted a review on the past, present, and the effect of health literacy on general society. Hence, the purpose of this study is to address the gap in the literature by reviewing studies related to the past, present, and the effect of health literacy.

\section{History OF HEALTH LITERACY}

The term "health literacy" is a relatively new term. It is derived from the umbrella term of "literacy", which is defined as: "The ability to use printed and written information to function in society, to achieve one's goals, and to develop one's knowledge and potential." ${ }^{[4]}$ Literacy became an emerging topic in the late 19th century because it was believed that nearly $20 \%$ of the American people were illiterate. ${ }^{[4]}$ The US congress passed the National Literacy Act of 1991 as an attempt to increase the literacy levels of American adults and defined the term "literacy" as "Individual's ability to read, write, speak in English, compute and solve problems at a level of proficiency necessary to function on the job and in society, to achieve one's goals and to develop one's knowledge and potential". ${ }^{[4]}$

After the enactment of the law, diverse definitions and measurements of literacy started to appear in civilian and military work-forces as these two sectors required their employers to be able to read and write appropriately in order for them to function in their jobs. ${ }^{[4]}$ Hence, the term "functional literacy" was coined. ${ }^{[4]}$ The advent of this term brought a wave of educational reforms in the United States. Throughout the 20th century, the way literacy was measured was relative to people's educational level and increasing demands of more complex jobs. ${ }^{[5]}$ For example, the US Census Bureau defined functional literacy as having at least a sixth-grade education in the 1980s, and most recently to a postsecondary education in the 2000s. ${ }^{[5]}$

In the 1980s, two leading literacy researchers published a study "Toward a Literate Society", which highlighted the fact that despite steadily increasing literacy levels, many Americans continued to suffer severely from deficient levels of comprehension and reading ability. ${ }^{[6]}$ In order for researchers to accurately accrue information in regard to people's literacy level, different organizations recognized the importance of developing a precise measure of literacy before implementing any future assistance programs addressing literacy. ${ }^{[5]}$ In 1985, the US Department of Education initiated a program called National Assessment of Educational Programs (NAEP), which was drafted to collect literacy data for Amer- ican adults in the age range between 21 and 25. ${ }^{[7]}$ In 1990, the US Department of Labor published a questionnaire and an assessment called "Literacy Proficiencies of Job Seekers". The purpose of this questionnaire was to better comprehend how working adults were understanding different forms of text. ${ }^{[7]}$ In 2003, the Department of Education introduced the National Assessment of Adult Literacy (NAAL) to specifically target the measurement of adults with limited literacy levels, who would need further education. ${ }^{[7]} \mathrm{NAAL}$ is still regarded as an important milestone for the field of health literacy because it was the very first national assessment that specifically included a section to measure health literacy for all American adults. ${ }^{[7]}$

The advancement of health literacy followed similar steps as literacy. With the focus of the medical field shifting from treating medical conditions to preventing the conditions in the 1960s, which overlaps with the 1964 Surgeon General's report on smoking, the term "health literacy" was born. ${ }^{\left[{ }^{8]}\right.}$ The emergence of health literacy allowed the focus of public health initiatives to change from modifying the generally poor working and living conditions of the industrial revolution to improving individual's health behaviors. ${ }^{[8]}$ This transition represented the importance of basic health and hygiene education and how it assisted the prevention of disease spread and promotion of better lifestyles for people residing in developed nations during the 1960s and 1970s. ${ }^{[9]}$

It became clear that researchers simply introducing assessment tools and providing large amounts of information, without considering the varying levels of socioeconomic status of people, was not helping the cause of increasing people's health literacy levels. ${ }^{[9]}$ Studies have shown that the majority of the health initiatives of the 1970s were only impactful to those with higher socioeconomic status who previously had exposure to education. ${ }^{[9,10]}$ Since then, many health literacy studies have identified factors such as economic, environmental, and social conditions and various policies as determinants of health. ${ }^{[10]}$ The Ottawa Charter for Health Promotion, which was held in 1986, showed this change by focusing its' meeting on the necessity of organization's commitment to health promotion. ${ }^{[1]}$ In this meeting, the term "good health" was defined as "a state of well-being that ideally should be achieved by all", instead of it being just a lifestyle choice. ${ }^{[1]}$

Since then, abundant studies focused on health literacy have presented enhanced definitions of health literacy and various interventions that could improve health literacy levels for patients with low health literacy levels. ${ }^{[12-14]}$ Similar to literacy, many researchers focusing their attention on developing studies and tools to be able to accurately assess patients' health literacy levels. While there are more than 
133 validated instruments measuring health literacy, ${ }^{[15]}$ the three assessment tools that are most widely used are: Test of Functional Health Literacy in Adults (TOFHLA), Rapid Estimate of Adult Literacy in Medicine (REALM), and Brief Health Literacy Screen (BRIEF). ${ }^{[16]}$

\section{Current status of health literacy}

The importance of health literacy has caught the attention of many healthcare researchers and organizations. Health literacy is now included as one of the measures of Consumer Assessment of Healthcare Providers and Systems (CAHPS) survey, and other organizations and agencies such as the Joint Commission, American Medical Association, and the Department of Health and Human Services have listed health literacy as an important component for healthcare quality and patient safety. ${ }^{[17]}$

Despite the fact that different healthcare organizations recognize the importance of health literacy, studies have demonstrated that the general population's health literacy levels are still low and limited. ${ }^{[18]}$ In a study conducted by Pleasant et al., ${ }^{[18]}$ a global survey was sent out to 300 researchers who primarily focused their research on health literacy. Even though the majority of the researchers did agree with the notion that health literacy was a topic requiring attention, almost half of those very researchers also stated that they believed the public's awareness of, and attention to, health literacy was still quite lacking. One of the main reasons is because the term "health literacy" does not have a set-instone definition. The American Medical Association's Ad Hoc Committee noted the term "health literacy" had existed for at least 30 years in a number of health-related literatures, without having a singularly clear definition. ${ }^{[9]}$ As a newer construct, it is not surprising that the definition of health literacy continues to evolve ${ }^{[9]}$ and that the term has been incorrectly used across several studies. ${ }^{[11]}$ Guyz et al. ${ }^{[11]}$ noted that this lack of consistency might be because health literacy is comprised of multiple attributes, which allows different people and researchers to prioritize certain attributes over others. One peer-reviewed article found out that of 17 health literacy studies published from 1999 to 2010, 13 used different definitions of health literacy. ${ }^{[4]}$ Of all the diverse definitions of health literacy, the definition from a 2004 Institute of Medicine report is the most commonly used throughout studies post-2010, which defined health literacy as "the degree to which individuals have the capacity to obtain, process, and understand basic health information and services to make appropriate health decisions". ${ }^{4]}$ While the definition of health literacy is becoming clearer, translating and comparing the meaning of health literacy in different languages is difficult since the conceptual comprehension of the term goes further than literal translation of words "health" and "literacy". ${ }^{[19]}$ In other words, because the words "health", and "literacy" can have different meanings in different languages, comparing the meaning of health literacy in other languages becomes increasingly problematic.

Despite advancements, low health literacy remains problematic in the United States. According to a report from the Annals of Internal Medicine in 2011, nearly 80 million adults in the US are believed to have inadequate health literacy levels. ${ }^{[13]}$ The impact of low health literacy is well documented. While research has shown that improving health literacy levels can enhance disease management behaviors, ${ }^{[20]}$ low levels of health literacy, on the other hand, can act as a barrier to communication, which can diminish patients' understanding of physicians' instructions. ${ }^{[21]}$ Low health literacy was defined as patients' inability to understand information in regards to managing disease. ${ }^{[21]}$ The lowered level of patient-physician communication, due to low level of health literacy, can lead to additional issues such as perceived intimidation, ${ }^{[22]}$ lessened patient engagement in their healthcare, ${ }^{[23]}$ or provider mistrust. ${ }^{[24]}$ All of these factors can lead patients with low health literacy to feel embarrassed when talking with physicians. ${ }^{[25]}$ This can bring negative consequences for an individual patient such as refusing to accept that he or she has a health problem or impeding them from asking questions in regard to their health. ${ }^{[25]}$ Additional studies have found that patients with low health literacy have experienced decreased levels of satisfaction at time of discharge. ${ }^{[26]}$ Moreover, patients with low health literacy have a difficult time deciphering medical discharge instructions or prescription labels ${ }^{[27]}$ and filling out forms necessary to obtain services, such as medication and insurance. ${ }^{[28]}$

\section{EFFECT OF LOW HEALTH LITERACY ON SOCIETY}

Understanding the epidemiology of low health literacy before understanding the actual effect of low health literacy levels in healthcare is imperative. ${ }^{[29]}$ Socioeconomic and racial determinants of health literacy are crucial to more clearly understand the complexity of health literacy that can affect demographically diverse groups. ${ }^{\text {[29] }}$ For example, a researcher cannot develop an intervention and state that it is going to be beneficial for people with different racial and ethnic backgrounds because the results of interventions may produce varying outcomes depending on race and ethnic background. ${ }^{[30]}$ This is demonstrated in numerous studies, which have observed an association between epidemiological factors and low health literacy levels. ${ }^{[29,30]}$

Four of the most commonly studied epidemiological factors 
are education, racial differences, age and physical impairments. There have been mixed results in terms of the association between health literacy and education, age and physical impairments. In terms of the association between education and low health literacy levels, Martin et al., ${ }^{[29]}$ reported that out of nine variables tested, low education level came out as the strongest predictor of inadequate health literacy levels. However, both Baker et al., ${ }^{[31]}$ and Taha, Sharit, \& Czaia ${ }^{[32]}$ stated in their studies that lower educational levels were not significantly associated with low health literacy levels. Similar trends are seen for age and impairments as well. ${ }^{[33]}$ Both Kobayashi et al., ${ }^{[34]}$ and Bostock and Steptoe ${ }^{[33]}$ reported increasing age and slowing in cognitive capabilities as strong indicators of limited health literacy levels. Furthermore, Shea et al., ${ }^{[35]}$ suggested that increasing age can be a strong predictor of low health literacy levels, but only when controlling for patients' educational levels. This proposes that age alone cannot be appropriate indicator of patients' health literacy levels. Out of the three epidemiological factors that have been most heavily researched, race is the only predictor studies have consistently reported to be a strong predictor of limited health literacy. Unfortunately, researchers have not discussed other possible predictors such as ethnic or cultural origins in this particular study. Chaudry et al. ${ }^{[36]}$ noted that there as a strong association between being African American and having inadequate health literacy. A similar result was obtained by Martin et al., ${ }^{[29]}$ who found Hispanics and African Americans had lower health literacy levels than non-Hispanic whites.

Previous studies examined how inadequate health literacy can affect patients' general health and performance of the US healthcare system. Inadequate health literacy levels have been associated with numerous health issues such as lower overall health, ${ }^{[37]}$ increased rate of obesity, ${ }^{[38]}$ worse management for HIV/AIDS patients, ${ }^{[13]}$ and increased use of health services. ${ }^{[37]}$ One specific aspect of low health literacy related to all of these phenomena is patients' inability to comport with a healthy lifestyle. By not being able to adhere to a positive lifestyle, patients will be more likely to engage in unhealthy eating habits, resulting in patients having a higher than average body mass index (BMI). James and colleagues ${ }^{[38]}$ found an association between limited health literacy levels and high BMI in a population of African American females who had a difficult time comprehending nutritional information. A similar result was observed within HIV/AIDS patients. HIV/AIDS patients with low health literacy levels were shown to have higher risk of medication nonadherence and worse self-reported health. ${ }^{[39]}$

Not only does limited health literacy level have an association with increased use of health services, it is also significantly

Published by Sciedu Press associated with lower utilization of preventative health services such as immunizations and an inability to adhere to a recommended medication and treatment. ${ }^{[13]}$ In other words, patients' limited health literacy levels can potentially have a negative impact on the US healthcare system. According to the National Institute of Health and Friedland's modeling assumptions, ${ }^{[40]}$ it was estimated that the effect of low health literacy cost the US healthcare system \$1.6 trillion to \$3.6 trillion, ${ }^{[41]}$ due to medical complications and readmissions.

\section{Conclusions}

The purpose of this review was to explore the literature related to the past, present, and the effect of health literacy. With COVID-19 affecting a huge number of population and its effect overwhelming the healthcare system, the role of health literacy and health education has become even more imperative. Unfortunately, even though the topic of healthcare quality improvement has been thoroughly studied for a long period of time, health literacy has rarely been thought of. Part of a reason for this phenomenon could be because the field and definition of health literacy is still evolving. ${ }^{[9]}$ However, the primary issue with health literacy is that at least half of Americans adults may not understand the complex medical communication used in the delivery of care, causing a wide-range of negative consequences such as disparities, costs, and care quality. ${ }^{[1]}$ Furthermore, studies have shown that patients' limited health literacy levels can cause patients to have longer length of stay in a hospital, higher chance of being readmitted, and higher chance of getting complications post-surgery. ${ }^{[26,42]}$

Hence, the direction of future research can be to create and observe the impact of health literacy interventions. A number of health literacy interventions exist, such as the teach-back method, eHealth intervention, and simplifying health information in educational materials. Future research can compare individual interventions to one another and see which are most effective. On the other hand, a new intervention can be generated to observe if it improves patients' health outcomes or observe how these interventions can impact overall quality improvement and financial status of their organizations. For example, a study conducted by Barad et al. ${ }^{[43]}$ showed that the decrease in average length of stay from 2.0 to 1.3 days resulted in $\$ 3,245$ of savings per patient in 2014 for a healthcare organization. Furthermore, additional study has shown that reduction in readmission rates have resulted in decrease in operating expenses for healthcare organizations. ${ }^{[44]}$

\section{Conflicts of InTERest Disclosure}

The authors declare they have no conflicts of interest. 


\section{REFERENCES}

[1] Institute of Medicine. Health Literacy: A Prescription to End Confusion. Washington, DC: The National Academies Press; 2004.

[2] National Center for Education Statistics. The Health Literacy of America's Adults: Results From the 2003 National Assessment of Adult Literacy. Washington, DC: U.S. Department of Education; 2006

[3] Kirsch IS, Jungeblut A, Jenkins L, et al. Adult Literacy in America: A First Look at the Results of the National Adult Literacy Survey (NALS). Washington DC: National Center for Education Statistics, U.S. Department of Education; 1993.

[4] Berkman ND, Davis TC, McCormack L. Health Literacy: What Is It? J Health Commun. 2010; 15(52): 9-19. PMid: 20845189. https://doi.org/10.1080/10810730.2010.499985

[5] Parker R, Ratzan SC. Health Literacy: A Second Decade of Distinction for Americans. J Health Commun. 2010; 15: 20-33. PMid: 20845190. https://doi.org/10.1080/10810730.2010.5010 94

[6] Carroll JB, Chall JS. Toward a Literate Society. New York: McGrawHill; 1975.

[7] Dewalt DA, Berkman ND, Sheridan S, et al. Literacy and Health Outcomes: A Systematic Review of the Literature. J Gen Intern Med 2004; 19: 1228-1239. PMid: 15610334. https://doi.org/10.1 111/j.1525-1497.2004.40153.x

[8] Nutbeam D. The Evolving Concept of Health Literacy. Soc Sci Med 2008; 67(12): 2072-2078. PMid: 18952344. https ://doi.org/10 .1016/j.socscimed.2008.09.050

[9] Nutbeam D. Health Literacy as a Public Health Goal: A Challenge for Contemporary Health Education and Communication Strategies into the 21st Century. Health Promot Int. 2000; 15(3): 259-267. https://doi.org/10.1093/heapro/15.3.259

[10] Kickbusch I, Maag D. Health Literacy. Int Encyl Public Heal. 2008; 204-2011. https://doi .org/10.1016/B978-012373960-5.0 0584-0

[11] Guyz D, Kenny A, Dickson-Swift V, et al. A Critical Review of Population Health Literacy Assessment. BMC Public Health. 2015 15(215): 1-7. PMid: 25885742. https://doi.org/10.1186/s1 2889-015-1551-6

[12] Liu H, Zeng H, Shen Y, et al. Assessment Tools for Health Literacy Among the General Population: A Systematic Review. Int J Environ Res Public Health. 2018; 15(8): 1711. PMid: 30103386. https://doi.org/10.3390/ijerph15081711

[13] Berkman ND, Sheridan SL, Donahue KE, et al. Low health literacy and health outcomes: an updated systematic review. Annals of Internal Medicine. 2011; 155(2): 97-107. PMid: 21768583. https : //doi.org/10.7326/0003-4819-155-2-201107190-00005

[14] Sorensen K, den Broucke SV, Fullam J, et al. Health Literacy and Public Health: A Systematic Review and Integration of Definitions and Models. BMC Public Health. 2012; 12: 80. PMid: 22276600. https : //doi.org/10.1186/1471-2458-12-80

[15] Duell P, Wright D, Renzaho AM, et al. Optimal health literacy measurement for the clinical setting: A systematic review. Patient Educ Couns. 2015; 98(11): 1295-1307. PMid: 26162954 https://doi.org/10.1016/j.pec.2015.04.003

[16] Wallston KA, Cawthon C, McNaughton CD, et al. Psychometric Properties of the Brief Health Literacy Screen in Clinical Practice. J Gen Intern Med. 2014; 29(1): 119-126. PMid: 23918160 https : //doi .org/10.1007/s11606-013-2568-0

[17] Rasu RS, Bawa WA, Suminski R, et al. Health Literacy Impact on National Healthcare Utilization and Expenditure. Int $\mathrm{J}$ Heal Policy Manag. 2015; 4(11): 747-755. PMid: 26673335. https: //doi.org/10.15171/ijhpm.2015.151
[18] Pleasant A, Cabe J, Patel K, et al. Health Literacy Research and Practice: A Needed Paradigm Shift. Health Commun. 2015; 30(12): 1176-1180. PMid: 26372030. https ://doi.org/10.1080/1041 0236.2015 .1037426

[19] Nutbeam D, Kickbusch I. Advancing Health Literacy: A Global Challenge for the 21st Century. Health Promotion International. 2000; 15(3): 183-184. https://doi.org/10.1093/heapro/15.3.183

[20] Zhang NJ, Terry A, McHorney CA. Impact of Health Literacy on Medication Adherence: A Systematic Review and Meta-Analysis. Annals of Pharmacotherapy. 2014; 48(6): 741-751. PMid: 24619949. https : //doi .org/10.1177/1060028014526562

[21] Gazmararian JA, Williams MV, Peel J, et al. Health Literacy and Knowledge of Chronic Disease. Patient Education and Counseling. 2003; 51(3): 267-275. https://doi.org/10.1016/S0738-399 1 (02) 00239-2

[22] Baker DW, Parker RM, Williams MV, et al. The Health Care Experience of Patients with Low Literacy. Archives of Family Medicine. 1996; 5(6): 329. PMid: 8640322. https ://doi.org/10.1001/ar chfami.5.6.329

[23] Golin C, Di Matteo MR, Duan N, et al. Impoverished Diabetic Patients Whose Doctors Facilitate Their Participation in Medical Decision Making are More Satisfied with Their Care. Journal of General Internal Medicine. 2002; 17(11): 866-875. PMid: 12406358. https://doi.org/10.1046/j.1525-1497.2002.20120.x

[24] Safran DG, Taira DA, Rogers WH, et al. Linking Primary Care Performance to Outcomes of Care. Journal of Family Practice. 1998; 47(3): 213-221

[25] Bernhardt JM, Cameron KA. Accessing, Understanding and Applying Health Communication Messages: The Challenge of Health Literacy. Handbook of Health Communication. 2003; 583-605.

[26] Kripalani S, Gatti ME, Jacobson TA. Association of Age, Health Literacy and Medication Management Strategies with Cardiovascular Medication Adherence. Patient Educ Couns. 2010; 81(2): 177-181. PMid: 20684870. https ://doi.org/10.1016/j.pec. 2010.04 030

[27] Wolf MS, Gazmararian JA, Baker DW. Health Literacy and Functional Health Status Among Older Adults. Archives of Internal Medicine. 2005; 165(17): 1946-1952. PMid: 16186463. https : //doi.org/10.1001/archinte.165.17.1946

[28] Gazmararian JA, Baker DW, Williams MV, et al. Health Literacy Among Medicare Enrollees, in a Managed Care Organization. JAMA, 1999; 281(6): 545-551. PMid: 10022111. https: //doi.org/10.1001/jama.281.6.545

[29] Martin LT, Ruder T, Escarce JJ, et al. Developing Predictive Models of Health Literacy. J Gen Intern Med. 2009; 24(11): 1211-1216. PMid: 19760299. https://doi.org/10.1007/s11606-009-1 105-7

[30] Lam LT, Yang L. Is Low Health Literacy Associated with Overweight and Obesity in Adolescents: An Epidemiology Study in a 12-16 Years Old Population, Nanning, China, 2012. Arch Public Health. 2014; 72(1): 11. PMid: 24685203. https://doi.org/10.1186/2049 $-3258-72-11$

[31] Baker DW, Parker RM, Williams MV, et al. The Relationship of Patient Reading Ability to Self-Reported Health and Use of Health Services. Am J Public Health. 1997; 87(6): 1027-1030. PMid: 9224190. https://doi.org/10.2105/AJPH.87.6.1027

[32] Taha J, Sharit J, Czaja SJ. The Impact of Numeracy Ability and Technology Skills on Older Adults' Performance of Health Management Tasks Using a Patient Portal. J Appl Gerentol. 2014; 33(4): 416-436. PMid: 24781964. https ://doi .org/10.1177/073346 4812447283 
[33] Bostock S, Steptoe A. Association Between Low Functional Health Literacy and Mortality in Older Adults: Longitudinal Cohort Study. BMJ. 2012; 344: e1602. PMid: 22422872. https://doi.org/10 $.1136 / \mathrm{bmj} \cdot \mathrm{e} 1602$

[34] Kobayashi LC, Smith SG, O'Connor R, et al. The Role of Cognitive Function in the Relationship Between Age and Health Literacy: A Cross-Sectional Analysis of Older Adults in Chicago, US. BMJ Open. 2015; 5(4): e007222. PMid: 25908675. https: //doi.org/10.1136/bmjopen-2014-007222

[35] Shea JA, Beers BB, McDonald VJ, et al. Assessing Health Literacy in African American and Caucasian Adults: Disparities in Rapid Estimate of Adult Literacy in Medicine (REALM) Scores. Fam Med. 2004; 36(8): 575-581.

[36] Chaudhry SI, Herrin J, Phillips C, et al. Racial Disparities in Health Literacy and Access to Care Among Patients with Heart Failure. J Card Fail. 2011; 17(2): 122-127. PMid: 21300301. https://doi.org/10.1016/j.cardfail.2010.09.016

[37] Kalichman SC, Rompa D. Functional Health Literacy is Associated with Health Status and Health-Related Knowledge in People Living with HIV-AIDS. J Acquir Immune Defic Syndr. 2000; 25(4): 337-344. https://doi.org/10.1097/00126334-200012010-00007

[38] James DCS, Harville C, Efunbumi O, et al. Health Literacy Issues Surrounding Weight Management Among African American Women: A Mixed Methods Study. J Hum Nutr Diet. 2015; Supple 2: 41-49.
[39] Osborn CY, Paasche-Orlow MK, Davis TC, et al. Health Literacy: An Overlooked Factor in Understanding HIV Health Disparities. Am J Prev Med. 2007; 33(5): 374-378. PMid: 17950402. https://doi.org/10.1016/j.amepre.2007.07.022

[40] Friedland R. New Estimates of the High Costs of Inadequate Health Literacy. Proceedings of Pfizer Conference "Promoting Health Literacy: A Call to Action". Washington, DC; 1998.

[41] Vernon JA, Trujillo A, Rosenbaum S, et al. Low Health Literacy: Implications for National Health Policy. Storrs, CT: University of Connecticut; 2007.

[42] Park NH, Song MS, Shin SY, et al. The Effects of Medication Adherence and Health Literacy on Health-Related Quality of Life in Older People with Hypertension. International Journal of Older People Nursing. 2018; 13(3): e12196. PMid: 29665241. https: //doi.org/10.1111/opn.12196

[43] Barad SJ, Howell SM, Joyce T. Is a Shortened Length of Stay and Increased Rate of Discharge to Home Associated with a Low Readmission Rate and Cost-Effectiveness After Primary Total Knee Arthroplasty? Arthroplasty Today. 2018; 107-112. PMid: 29564377. https://doi.org/10.1016/j.artd.2015.08.003

[44] Upadhyay S, Stephenson AL, Smith DG. Readmission Rates and Their Impact on Hospital Financial Performance: A Study of Washington Hospitals. Inquiry. 2019; 56: 0046958019860386. PMid: 31282282. https://doi.org/10.1177/0046958019860386 